\title{
Interaction Between Oryctes Rhinoceros and Leaves' Nutrient Content in Oil Palm
}

\author{
Fathul Nabila, $\mathrm{AK}^{1}$, Mohd Rasdi, $\mathrm{Z}^{2}$, Nurul Farahana Hazira, $\mathrm{H}^{3}$ \\ 1,3Dept of Entomology, Faculty of Plantation and Agrotechnology, Universiti Teknologi MARA (UiTM) Shah \\ Alam, Selangor, Malaysia
}
${ }^{2}$ Agriculture Entomology and Associate Professor, Faculty of Plantation and Agrotechnology, Universiti Teknologi MARA Cawangan Melaka, Merlimau, 77300, Melaka, Malaysia

\begin{abstract}
A study meant to evaluate the relationship between the presence of Oryctes rhinoceros to the oil palm in relation to the leaves' nutrient content which is Phosphorus $(\mathrm{P})$ and Potassium $(\mathrm{K})$. Appropriate fertilization is one of the methods that can help to suppress the pests' presence in the field. In general, insects' pests are attracted to the plants that are supplied with excess supply of nutrient as it can help them to develop better in future as these nutrient play their roles in aiding through growths and insects' fecundity. Data on nutrient status were collected were Phosphorus (P), Potassium (K), Calcium (Ca), Magnesium (Mg), Copper (Cu) and Zinc (Zn). These data had been collected twice per month which were at the middle and at the end of each month. Four samples of leaves were taken from four sampling oil palm trees of each treatment. Leaves from ninth or seventeenth fronds were chosen as it is the best most ideal fronds to be used for leaf analysis to identify the nutrient content. The result of this study showed that Phosphorus $(\mathrm{P})$ exerted a strong positive relationship with the presence of Oryctes rhinoceros in the oil palm while Potassium $(\mathrm{K})$ showed a strong negative relationship between the two variables. Thus, developing awareness to the growers to this nutrients-balancing issue would be good for future agriculture in future as it is clear now that balanced nutrition is primordial to ensure availability of nutrients uptake by plants.
\end{abstract}

Indexing terms/Keywords: Oil Palm; Oryctes rhinoceros; nutrient content; Phosphorus (P); Potassium (K)

Subject Classification: Agriculture and entomology

Type (Method/Approach): Crop protection

Supporting Agencies: Universiti Teknologi MARA

Date of Publication: 2018-08-30

DOI: https://doi.org/10.24297/jaa.v8i1.7585

ISSN: 2349-0837

Volume: 08 Issue: 01

Journal: Journal of Advances in Agriculture

Publisher: CIRWORLD

Website: https://cirworld.com

This work is licensed under a Creative Commons Attribution 4.0 International License. 


\section{Introduction}

Oryctes rhinoceros, or well-known by its common name which is coconut rhinoceros beetle plays a major role that act as a main pest to oil palm. Oryctes rhinoceros roughly feeds on fifty-one plant species which belong to ten families. Out from fifty-one, thirty-seven is recorded belongs to the family of Arecaceae, which is the most preferred by these beetles. Being a pest to nearly fifty-one plant species in the world, a solution must come out to decrease these populations.

Balanced nutrient supply is important in producing a high quality plants. These balanced nutrient interactions ensure the plants to be resistance and have its own defense mechanisms against any pests or diseases (Spann and Schumann, 2013). If a plant is diverged from its required optimum nutrients level, these plants has a high possibility to be susceptible and vulnerable to be attack by pests and disease.

Nutrient supply or the concentration of the nutrients has the ability in having interaction with the pest presence (Huber et al., 2012). As revealed by Mohd Rasdi et al. (2013) variation in the nutrient concentration of a plant would give an impact towards the plants' physiological performance where it will lead to the pests' population alteration. A study by Altieri and Nicholls (2003) summed up that susceptibility of a plant can be inferred from a fertilization activity as it changes the nutrient level of the plants' tissues.

\section{Materials and Methods}

\section{Experimental Design and Collection of Data}

This study was conducted for the purpose to determine the relationship between the population of Oryctes rhinoceros and the leaves' nutrient content in the palm oil field. Data on nutrient status were collected were Phosphorus (P), Potassium (K), Calcium (Ca), Magnesium (Mg), Copper (Cu) and Zinc ( $\mathrm{Zn})$. These data had been collected twice per month which were at the middle and at the end of each month.

Four samples of leaves were taken from four sampling oil palm trees of each treatment. Leaves from ninth or seventeenth fronds were chosen as it is the best most ideal fronds to be used for leaf analysis to identify the nutrient content (Fairhurst and Mutert, 1999). The samples then were wiped and being kept in the zip locks. Subsequently, the samples then were brought back to the Soil Laboratory, Faculty of Plantation and Agrotechnology in Universiti Teknologi MARA (UiTM) Campus Jasin, Melaka for further analysis.

To determine the nutrient content in the leaves, the method used was Dry Ashing Method (Kalra, 2000).

Procedures of Dry Ashing Method in Determining Leaves' Nutrient:

First, the collected leaves samples were dried in an oven at $60^{\circ} \mathrm{C}$ for 24 hours to a constant weight. Secondly, the leaves samples were grinded using a grinder machine. Then, $0.5 \mathrm{~g}$ of the samples was placed in crucibles. Next, the samples were ashed in a muffle furnace for the first hour at $300^{\circ} \mathrm{C}$. The next second to sixth hour was at $550^{\circ} \mathrm{C}$. The samples then were moistened by adding a few drops of distilled water. $2 \mathrm{~mL}$ of Hydrochloric acid $(\mathrm{HCl})$ was added to the samples and was evaporated on a hot plate. Later, $10 \mathrm{~mL}$ of $20 \% \mathrm{HNO}_{3}$ (200 milliliters concentrated $\mathrm{HNO}_{3}$ in 1000 milliliters distilled water) were added. Subsequently, the crucibles were heated in the water bath for 30 minutes at $100^{\circ} \mathrm{C}$. After that, the samples in the crucibles were diluted to 100 milliliters using a volumetric flask. The samples then were filtered into a 100 milliliters vials. Lastly, the nutrient content of the leaves samples was analyzed using Inductively Coupled Plasma (ICP) (Optima 8300DV).

\section{Data Analysis}

The main objective in this Chapter was to determine the relationship between the presences of Oryctes rhinoceros with the leaves nutrient content in the palm oil field. To achieve the objective, correlation analysis of Statistical Package for Social Science (SPSS - version 23) were used. 


\section{Results and Discussion}

\section{Relationship Between Oryctes rhinoceros and Phosphorus (P) Level in Oil Palm's Leaves}

As demonstrated in Figures 1,2 and Figure 3, there was a very strong positive relationship $(r=0.345 ; P<0.01)$ between the mean population of Oryctes rhinoceros and the mean Phosphorus $(P)$ level in oil palm's leaves. It showed a trend where an increase in mean Phosphorus $(P)$ level in the leaves lead to a high mean population of Oryctes rhinoceros in the field.

In Figure 1, for the first six months, as the content of mean Phosphorus $(P)$ in leaves decreased, the mean number of Oryctes rhinoceros also went to decrease. At the end of February, the mean Phosphorus (P) content showed an increase from $7.04 \mathrm{mg} / \mathrm{L}$ to $7.45 \mathrm{mg} / \mathrm{L}$ and the mean population of Oryctes rhinoceros was also increased from 2 to 5.75 . The highest mean population of Oryctes rhinoceros recorded was 6.75 which were on 15th April 2017 and the lowest was at 0.75 . Both parameters in Figure 5.1 were fluctuated within that ten months' time.

As for Figure 2, during the first six months, the mean population of Oryctes rhinoceros presence was unpredictable as it went up and down but this trend stopped on 15th February 2017 where the mean population of the beetles increased for a month until 15th March 2017. However, this mean population of Oryctes rhinoceros went down from 4 to 1.25 on 15th April 2017.

Starting from this point, the mean population of Oryctes rhinoceros became fluttered and unpredictable as it showed a 'yo-yo' situation until on 30th June 2017 where the mean of Oryctes rhinoceros became consistent showing an increase where 4.75 was recorded to be the highest with $8.14 \mathrm{mg} / \mathrm{L}$ for mean Phosphorus (P) level in leaves along the sampling period. Nevertheless, after showing a persistent increment, the mean presence of the beetles dropped drastically to 1 and it was the lowest mean of Oryctes rhinoceros recorded in Figure 5.2 and the mean Phosphorus (P) level at this point was at $7.32 \mathrm{mg} / \mathrm{L}$. It can be clearly seen that the Phosphorus (P) content was fluctuated with minimal differentiation within the sampling period.

As for Figure 3, it was clearly shown that the mean presence of Oryctes rhinoceros was relatively low among all the sampling period. The highest mean for the Oryctes rhinoceros was between the range 0.75 and 1 . The same goes for the mean Phosphorus (P) level as it stayed low at all times with the highest mean recorded was 8.63 $\mathrm{mg} / \mathrm{L}$ and the lowest was at $4.59 \mathrm{mg} / \mathrm{L}$.

\section{Relationship Between Oryctes rhinoceros and Potassium (K) Level in Oil Palm's Leaves}

Figures 4,5 and 6 revealed that the mean population of Oryctes rhinoceros has a strong negative relationship ( $r=-0.674 ; P<0.01)$ between the mean Potassium $(K)$ level in leaves. When the mean content of Potassium (K) decreased, the mean population of Oryctes rhinoceros increased.

Figure 4 revealed both parameters, the mean population of Oryctes rhinoceros and mean Potassium (K) level in leaves were oscillated in that ten months of sampling period. For the first one month, the mean level of Potassium $(K)$ increased from $30.42 \mathrm{mg} / \mathrm{L}$ to $35.57 \mathrm{mg} / \mathrm{L}$ which made the mean population of Oryctes rhinoceros to decrease from 2.75 to 2 . After that, it can be seen from the mean population of the beetles went to increase up to 5.75 and as the mean Potassium (K) level followed the opposite rule, the mean content went down from $35.57 \mathrm{mg} / \mathrm{L}$ to $32.85 \mathrm{mg} / \mathrm{L}$.

On 15th April 2017, it was the highest presence on the mean of Oryctes rhinoceros which was at 6.75 with $24.57 \mathrm{mg} / \mathrm{L}$ recorded for the mean Potassium (K) level in the oil palm leaves. After 15th April 2017, the mean presence of the Oryctes rhinoceros kept decreased for almost a month and thenceforth, both parameters went oscillated and it could not be expectable. Yet, after being unpredictable, there was a rapid decrease on the mean population of the beetles on 15th September 
2017 from 6.25 to 0.75 and antagonistically, the mean of Potassium (K) went up from $24.72 \mathrm{mg} / \mathrm{L}$ to $33.76 \mathrm{mg} / \mathrm{L}$ as these parameters have a negative connection.

As expressed in Figure 5, the first one month, the mean population of Oryctes rhinoceros increased but the viceversa happened to the mean Potassium $(K)$ level in leaves. Upon entering the first two weeks in the second month, the mean population of the beetles felled down from 3.5 to 1 and at this point, the mean Potassium (K) level in leaves boosted up from $27.72 \mathrm{mg} / \mathrm{L}$ to $32.73 \mathrm{mg} / \mathrm{L}$. However, at the end of the second month, the mean population of the Oryctes rhinoceros increased again to the mean number of 4 whereas the mean level of Potassium (K) was equal to $24.52 \mathrm{mg} / \mathrm{L}$. Starting from this point, the mean number of Oryctes rhinoceros became unpredictable with the highest mean recorded was 3 and the lowest was 1.25. The same went to the mean level of Potassium $(K)$ where it varied depending to the mean population of the beetles.

Anyhow, this inconsistency stopped on 30th July 2017 where the mean number of the Oryctes rhinoceros started to show an increase trend for two consecutive months but it went oppositely happen to the mean level of Potassium (K).

Conversely, after showing a stable increased trend for that two following months, the mean number of the beetles dropped dramatically from 4.75 to 1 . Inversely, the mean level of Potassium (K) started to incline from $25.43 \mathrm{mg} / \mathrm{L}$ to $35.06 \mathrm{mg} / \mathrm{L}$.

As shown in Figure 6, it was clearly seen both parameters were in a persistent trend. Both parameters were predictable since there were no obvious variations in both parameters. The highest mean population for Oryctes rhinoceros was 0.75 and the lowest was at zero $(0)$. As for mean level of Potassium $(K)$, the highest value recorded was $38.82 \mathrm{mg} / \mathrm{L}$ and the lowest was at $29.13 \mathrm{mg} / \mathrm{L}$.

The result of this study showed that Phosphorus (P) did give a significant effect towards the presence of the Oryctes rhinoceros in the oil palm areas. To have a high quality of crop production, adequate mineral nutrition is required. Phosphorus $(P)$ is one of the main macronutrients and it plays some important roles in plants. Adequate Phosphorus $(P)$ requirement by the plants will ensure the plants to have a better quality, lengthen the growth of the roots, fasten the maturity of the plants, strengthen the plant's stalk and eventually produced higher grains. As it is one the nucleic acid component, it does play roles for reproduction process where plants productions and yield do really matters. However, Phosphorus $(P)$ application can decrease or increase the disease and also the pest developments (Parthasarathy, 2015).

Stated by Parthasarathy (2015), from $28 \%$ cases examined, pests and diseases problems had occurred due to the high Phosphorus (P) applications. Indeed, crop plants such as the maize, cucumber and rice showed resistance to pathogen as a result of phosphate salts applications.

Besides, Phosphorus $(\mathrm{P})$ content has a strong positive relationship with the pest's presence as this aspect has a connection the plants secondary metabolites. Phosphorus $(P)$ content is said to have a connection with the phenolic content of the plants. Recently, there are several studies claiming that low Phosphorus $(P)$ content would lead to high production of secondary metabolites which is phenolic. With high phenolic production, less presence of Oryctes rhinoceros is presence in the field. Naturally, a vulnerability of a plant towards pests' attacks will be altered when there is a change in the concentration of the nutrition. Walling (2000) suggested that a plant that produce secondary metabolites would have the potential in giving particular cues or signals which would captivate the parasites and also predators.

Reductions of yields in crops are often reported due to imbalanced fertilizer in fields. According by Moschler and Martens (1975), interaction between Phosphorus (P) and Nitrogen (N) can help to increase the yields gained by the producers. However, this interaction can be easily disrupted by the structure or textures of the soils. Combinations of fertilization between these two nutrients are crucial as it helps to boost the amounts of yields by increasing the number of cobs per plants, number of grains per cob and increase the grains weight. Not only 
that, interactions of these nutrients also increases the crops' height (Khan et al., 2014). In his study, he stated that when Phosphorus $(\mathrm{P})$ and Nitrogen $(\mathrm{N})$ are combined with ratio of 100:100 per hectare, maximum numbers of cobs per plant were obtained. This finding was in line with the same result obtained by Bakht et al. (2007) and Abbas et al. (2005). Khan et al. (2014) also reported that the grains also increased from $1519 \mathrm{~kg} / \mathrm{ha}$ to 5356 $\mathrm{kg} / \mathrm{ha}$ when there is a combination between Phosphorus $(P)$ and Nitrogen $(N)$ with a ratio of $150: 100 \mathrm{~kg} / \mathrm{ha}$. It is supported by Krishnamoorthy and Madagaleri (2000) stated that oil yield of Trachyspermum ammi L. (Ajowan) has a positive relationship with Phosphorus $(P)$ - Nitrogen $(N)$ interaction. Maxiumum Phosphorus $(P)$ - Nirogen $(N)$ interation rate also did increase the plants' height up to $256 \mathrm{~cm}$ when the ratio was $150: 150 \mathrm{~kg} / \mathrm{ha}$. It was proposed that increased in root growth that strengthened the stem had helped the plant to increase its height.

Finding of this study revealed that Potassium does have an effect towards the Oryctes rhinoceros' presence. Potassium $(\mathrm{K})$ is one of the nutrients that contribute to increase the tolerance of the plants towards insects' pests (Amtmann et al., 2008; Sarwar, 2012 and Singh et al., 2003). Amtmann et al. (2008) and Wang et al. (2013) also emphasized that application of Potassium $(K)$ has a potential to reduce the damage and incidence of bacterial, fungi and as well as pests. According to Rashid (2016) in his study on rice, Potassium (K) fertilization helps to decrease free sugar and proteins in the plant tissue thus helps the rice to be less susceptible to brown plant hopper, an herbivorous insect. Through a study by Kulagod et al. (2011), also stressed that Potassium (K) helps the rice to be resistance towards the leafhoppers and application of Potassium (K) also can reduce the damage done by the blue beetle. Besides, Sarwar (2012) also declared that Potassium (K) has been proved to refine the rice to be more tolerance towards lodging, insects' pests and boost the yield of the rice and further helps to enhance the environment by reducing the use of pesticide.

A research by Flechtmann and Malavolta (1976) asserted that from his study that Potassium (K) nutritional status on host plant does affect the mite population where the result from the study showed that there is a negative relationship with the increasing Potassium $(K)$ content with the population of the mites. Potassium plays a crucial role that involves essential processes in the plants such as for the transportation of carbohydrate, synthesis of proteins, carbohydrates and starches. According to Amtmann et al. (2008), Potassium (K) will exert a real effect on plants' hormonal, biological and physiological processes which will be pivotal for the plants' susceptibility towards the disturbance of pests of diseases. Potassium $(\mathrm{K})$ will determine the attractiveness of the plants to insects' pests as it has the effect on the distribution and the profiles of the primary metabolites. For protein synthesis process, when there is an adequate supply of Potassium $(K)$ in plants, the raw materials of Nitrogen (N) such the nitrates and amino acids will be accumulating in the plants where it will be not converted into protein. This disturbance will have resulted in lower quality of end-products like grains and forages (RanadeMalvi, 2011).

Besides, Potassium (K) also involves in plant defense system. As stated by Walling (2000), plants can produce volatile compounds that act as a chemical defence to the plants. One of those volatile compounds is Cisjasmone. Structurally, Cis-jasmone is related to methyl jasmonate and jasmonic acid. In addition, Cis-jasmone has the capacity to produce volatile chemical signals without doing any harm to the plants physiological processes. Amtmann et al. (2008) reported that when there is a Potassium (K) deficiency in plants, jasmonic acid market genes will be increased. Plants protect themselves from herbivorous insects by using jasmonic acid. According to Shivaji et al. (2010), a vast genes number are involved to help the plant' defensive system is regulated by jasmonic acid.

Nutrient balancing in plants systems are crucial for a healthy plants' development. To maintain a continuous growth of a plant, there must be an interaction occurs between all those nutrients. Two nutrients are interacting when crops' responses to one nutrient are relying to another adequate supply of another nutrient. These interactions will determine the ratios of nutrients needed by the plants and these ratios are particularly leaning on plants' environments, life cycle and others. As noted by Johnston and Milford (2012), there is no use in saving one nutrient supply as it will affect another nutrient's availability to the plants. In balancing the nutrients required, it need an interaction to occur which this interaction depends on the $\mathrm{pH}$ of the soils, suitable temperatures, soil properties and several other factors. Balancing the ratios of these nutrients is much more difficult than only focusing on one single nutrient concentration. 


\section{Conclusions}

The results of this study showed that Oryctes rhinoceros presence in the oil palm has a positive relationship with Phosphorus (P) and showed a negative relationship when it is related with the Potassium (K). Thus, this study proposed that a balanced fertilization must be done and taught to the growers as it is the key to gain maximum efficiency in the usage of nutrients and also enhancing crops productions. Developing awareness to the growers to this nutrients-balancing issue would be good for future agriculture in future as it is clear now that balanced nutrition is primordial to ensure availability of nutrients uptake by plants.

\section{Acknowledgments}

I would like to express my highest gratitude to my main supervisor, Assoc. Prof. Dr. Mohd Rasdi Zaini for all his ideas, helps and guidance to me that had help me to complete this research.

\section{References}

1. Abbas, G., Hussain, A., Ahmad, A. and Wajid, S.A. (2005). Effect of irrigation schedules and nitrogen rates on yield and yield components of maize. Journal of Agriculture \& Social Science, 1, 335-338.

2. Altieri, M. A., \& Nicholls, C. I. (2003). Soil fertility management and insect pests: harmonizing soil and plant health in agroecosystems. Soil and Tillage Research,72(2), 203-211.

3. Amtmann, A., Troufflard, S., and Armengaud, P. (2008). The effect of potassium nutrition on pest and disease resistance in plants. Physiologia Plantarum, 133(4), 682-691.

4. Bakht, J., Siddique, M.F., Shafi, M., Akbar, H., Tariq, M., Khan, N., Zubair, M. and Yousef, M. (2002). Effect of planting method and nitrogen levels on the yield and yield components of maize. Sarhad Jounral of Agriculture, 23, 553-559.

5. Fairhurst, T.H., and E. Mutert. (1999). Interpretation and management of oil palm leaf analysis data. Better Crops International.13(1):48-51.

6. Flechtmann, C.H.W. and Malavolta, E. (1976). Studies on the mineral nutrition of grain sorghum. III. Populations of the common two spotted spider mite on grain sorghum grown on various levels of $N, P$ and $K$. Communications in Soil Science and Plant Analysis, 7 (9), 839-841.

7. Huber, D., Romheld, V. and Weinmann, M. (2012). Relationship between nutrition, plant disease and pests. Marschner's Mineral Nutrition of Higher Plants, 283-298.

8. Johnston, A.E. and Milford, G.F.J. (2012). Potassium and nitrogen interaction in crops. Retrieved from https://www.pda.org.uk/technical potash-notes/potassium-and-nitrogen-interactions-in-crops/.

9. Kalra, Y.P. (2000). Handbook of reference methods for plant analysis. CRC Press, NW Corporate BVLO, Boca Raton, Florida.

10. Khan, F., Fahad, S., Faisal, S. and Hussain, S. (2014). Effect of different levels of nitrogen and phosphorus on the phenology and yield of maize varieties. American Journal of Plant Science, 5, 2582-2590.

11. Kulagod, S.D., M.G. Hedge., G.V. Nayak., A.S. Vastrad, and P.S. Hugar. (2011). Influence of fertilizer on the incidence of insect pests in paddy. Karnataka J. Agric. Sci. 24(2): 241-243. 
12. Krishnamoorthy, V. and Madagaleri, M.B. (2000). Effect of interaction of nitrogen and phosphorus on seed and essential oil yield of ajowan (Trachyspermum ammi.L) genotype. Journal of Spices and Aromatic. 9(2), 137139.

13. Mohd Rasdi, Z., Che Salmah, M.R. and Abu Hassan, A.(2013). Effect of nutrient and pre - infested brinjal, Solanum melongena by whitefly and aphid on population dynamics of whitefly, Bemisia tabaci. Agriculture, Forestry and Fisheries, 2(1), 1-10.

14. Morales, H., Perfecto, I. and Ferguson, B. (2001). Traditional soil fertilization and its impact on insect pest populations in corn. Agric.Ecosyst.Environ.84,145-155.

15. Moschler, W.W. and Martens, D.C. (1975). Nitrogen, phosphorus and potassium requirements in no-tillage and conventionally tilled corn. Soil Science Society of America, Proceedings, 39, 886-891.

16. Nevo, E. and Coll, M. (2011). Effect of nitrogen fertilization on Aphis gossypii (Homoptera:Aphididae): variation in size,colour, and reproduction. J. Econ.Entomol.,94,27-32.

17. Parthasarathy, S. (2015). Effect of fertilizers on plant diseases. Retrieved from http://agropedia.iitk.ac.in/content/effect-fertilizers-plant-diseases

18. Ranade-Malvi, U. (2011). Interaction of micronutrients with major nutreints with special reference to potassium. Karnataka. J.Agric.Sci., 24(1), 106-109.

19. Rashid, M. M., Jahan, M., \& Islam, K. S. (2016). Impact of Nitrogen, Phosphorus and Potassium on Brown Planthopper and Tolerance of Its Host Rice Plants. Rice Science,23(3), 119-131.

20. Sarwar, M,. (2012). Effects of potassium fertilization on population build up of rice stem borers (lepidopteran pests) and rice (Oryza sativa L.) yiled. J Cereals Oilseeds,3,6-9.

21. Shivaji, R., Camas, A., Ankala, A., Engelberth, J., Tumlinson, J.H., Williams, W.P., Wilkinson, J.R. and Luthe, D.S. (2010). Plants on constant alert: elevated levels of jasmonic acid and jasmonate-induced transcripts in caterpillarresistant maize. J.Chem.Ecol., 36, 179- 191.

22. Singh B, Singh Y, Imas P, Chang X.J. (2003). Potassium nutrition of the rice- wheat cropping system. Advances in agronomy, Academic press, 81,203-259.

23. Spann, T.M. and Schumann, A.W. (2013). Mineral nutrition contributes to plant disease and pest resistance. University of Florida, 1-4.

24. Walling, L.L. (2000). The myriad plant responses to herbivores. Department of Botany and Plant Science, University of California, Riverside, California 92521-0124.JPGR.Journal of Plant Growth Regulation,19,195-304.

25. Wang, M., Zheng, Q., Shen, Q. and Guo, S. (2013). The Critical Role of Potassium in Plant Stress Response. International Journal of Molecular Sciences. 14(4), 7370-7290. 